\title{
The Impacts and Implications of ISO 26000 "Guidance of Social Responsibility on the Lebanese Industries"
}

\author{
Saher H. EL-Annan PhD, Mohamad Khodor Chamas (MBA) \\ Arab Open University Tayouneh Omar Bayhom Street - the Park sector Badaro-Beirut- 2058 -4518 -Lebanon \\ Certified ISO Master Trainer
}

\begin{abstract}
Summary: There is still a confusing comprehension of what social responsibility and corporate responsibility incorporate. ISO 26000, an international guidelines social responsibility, was launched on $1^{\text {st }}$ of November in the year 2010. This initiative was focused on contributing to global sustainable development that was targeted at encouraging any kind of organizations to exercise responsibilities in a holistic approach. Through improving the governance of the organization that ensures the welfare of employees, respect human rights, natural environment as well as fair operating practices, consumer health and communities' involvement and development. In relation to social responsibility to Lebanese industries, these international standards were meant to revolutionize the industrial operation in the country to shift the business strategy to sustainable strategy putting into consideration that most of the industries in this country are family business and as one of the Arab countries where corporate governance, as well as social responsibility, are hardly followed.
\end{abstract}

Keywords: ISO 26000, corporate social responsibility, sustainable development.

\section{Problem Statement}

Lebanon is an Arab country that hardly adheres to social responsibility rules. There are stipulations that many of the chief executive people who are employed in this country are men since they are given the first priority while women in most cases are not considered so much. According to Azer (2002), the ethics of corporate responsibility, there are many cases of violation of social responsibilities of workers and men of the elite and high social class who have the power to control every system in the country's industrial operations. Many researchers have confirmed Lebanon is one of the countries where social norms, culture and beliefs of the country allow men of the high social class to hold the managerial position in most of the companies.

\section{Research Objectives}

The core objectives that this research is meant to achieve include:

1. To establish ISO 26000 standards impact to the Lebanese industries.

2. To establish the implications in relation to the implementation of ISO 26000 standards to the Lebanese industries.

3. To research on how social responsibility has been affected by failures the non-adoption of the ISO 26000 standards at macro level.

4. To point out the benefits of ISO 26000 standards to the employee, employers and their companies, community and environment.

\section{Literature Review}

According to Schwarz and Tilling (2009), the ISO 26000 requirements advocate for the seven principles of socially responsible behavior: accountability whereby, every company has an obligation to account for the impact of the products, by-products and general influence of the company to the workers, community and environment. Concerning Lebanon, many industries lack accountability in the above-mentioned three areas that have resulted to deplorable lives among the low class Lebanese citizens. Besides, it has facilitated to slow economic growth.

The second principle is transparency whereby, the ISO 26000 standards enforce transparency in terms of stipulating the general working conditions of the workers where every worker is entitled to information concerning their welfare, health issues and benefits schemes. In reference to Snider, Ronald and Martin, (2003), every company should clearly stipulate the impact of the operation of the company to the community both health wise, economic wise and social wise. Finally, the company should inform the public about its impact on the environment and outline possible mitigation strategies to the effects that might be brought about by the operation of the company. The third key principle is the ethical behavior whereby all the employers and the employees should adhere to the set ethical behavior. Additionally, the top industrial management's watchdog should ensure that both the owner of the companies and the employees stick to the set industrial operational standards. In regards to Lebanese industries, the elite control a big share of the industrial top jobs. Besides, the 
board of directors comprise of the renowned elites who have the power to influence their re-election to power. There are more cases of bureaucracy leading to poor performance of industries since most of the resources revolve around the rich. As a result, the international industrial operation standards are not put into consideration since most of the top management comprises of people with selfish motives. Furthermore, it has been cumbersome for the state to implement such standards since ISO 26000 is not adopted by the government policy at macro level. This essence of bureaucracy has been the core influential factor that deters the implementation of the ISO 26000 standards.

According to Schwarz and Tilling (2009), the fourth key principle of ISO 26000 is the respect for the stakeholder's interest. Stakeholders refer to both the individuals and groups that are mostly affected or rather have the ability to influence the general actions of the organization. In reference to Lebanese industries, this group of people is made up of common civilians that have no reputable say upon the poor decisions made by the key, industrial personnel. They are hardly heard and most of them live a dilapidated life that is below average in some cases. They are the ones that are on the verge of encountering the primary effects of environmental pollution resulting from deliberate negligence by the elite who are the decision makers of the Lebanese industries. This negligence of enforcing the ISO 26000 standards has deteriorated the social responsibility of the main stakeholders who are the workers and the community. It has resulted to uncontrollable environmental conditions that have become costly to the country in terms of implementing mitigation strategies.

Hahn (2012) argues that what forms the fifth principle of ISO 26000 in relation to the social responsibilities and Lebanese industries is the respect to the law. About this principle, many Lebanese bureaucrats do not have respect for the law because the minorities who are the civilians and women have no say upon the decision made by the men who are in extreme political powers. Lantos, (2002) affirms that failure to respect the rule of law has been proven to be a serious influence to enforce and implement the adoption of the ISO 26000 standards since most of the people who are in power are influenced by their personal interests and they consider the adoption of the standards as an expensive endeavor that the country cannot afford. Again, due to the fact that most of the Lebanese are made up of middle-low class and low-class people, the few ruling elite groups presumes that implementing the standards will see these civilians receive freedom in terms of better social responsibility measures and care for both the society and environment in general.

The fifth principle is the respect to the international norms of behavior. In reference to Lebanon, the country is among the Arabic countries that believe in the Arabic rule of law. This is whereby the women still have marginal right at for any high positions in the country as opposed to the international stipulations/equal opportunity. Again, the minority groups like the low income, handicapped, and illiterates have limited space to propose what is right, but instead, the very prominent people holding top management positions in the country, where they have the power to put forth and implement what they wish. Therefore, this lack of respect to the international behaviors has resulted in a situation whereby international requirements are not considered of great significance to the general well-being of the country and its citizens. Lastly according to Hahn (2012), the respect for human rights form a pivotal principle within the ISO 26000 provisions whereby in regard to Lebanon laws, which is an Arabic country, the female gender has still yet to have the right of free expression equal to the male gender especially in terms of leadership. The enforcement of such laws in the Lebanese nation has dragged behind the advancement of women since they are restricted from pursuing other types of careers and projects that can help to enhance the livelihood in the country. According to Page (2005), corporate governance and value creation can be achieved if every user of ISO 26000 will put into consideration the following subjects that are of great significance in ensuring social responsibility. The Lebanon government, despite the massive efforts that have been invested by the civil societies and the private sector, has dismissed some of these subjects. These subjects include; organizational governance, which refers to the framework of set rules that a board of directors ensures accountability, just, as well as transparency in an organizational relationship with its customers, financiers, management, employee's government and the community. Organizational governance strategy entails the explicit as well as implicit contracts between the enterprise and the stakeholders for both the distribution of responsibilities rewards as well as rights. The details of this subject have been evaded by the Lebanese industries, which has led to poor performance in terms of ISO 26000 standards. This is because the top management in the country has neglected the proposed international requirements that could see the enhancement of industrial accountability to the environment, fairness and transparency to the welfares of the workers and the benefits that are expected to be extended to the community. The other subjects are enforcement of human rights and labor practice whereby it has been recorded that Lebanon has had improvement concerning human rights. However, most research still indicates that there are still rampant cases involving abuse of detainees. After the withdrawal of Syrian troops amounting to about 25000 from Lebanon in 2005 led to the enhanced freedom of speech, although, there are still cases involving excessive use of forces by Lebanese security for people having a peaceful demonstration. According to Luetkenhorst (2004), failure to enforce corporate social responsibility as well as transformational agenda to the 
subject of human rights, the ultimate results is the massive violation of human right and derailment of civil society efforts that is focused on enhancing the understanding and implementation of human right Acts.

Researchers have published credible reports confirming that Lebanon is one of the global countries that still perpetuate abuse of domestic female workers especially the immigrants. It has been established that the foreign domestic workers in Lebanon are compelled to work for long hours and at the time they are abused and they are hardly paid their wages which lead them committing suicide by falling from the balconies or hanging themselves. Reports from the public domain and social media have confirmed that many domestic workers are deported from east African countries and part of Asia to work in Lebanon and some of these workers are compelled to commit immoral behaviors. For instance, those that fail to cope with the requirements of their employers, they are mistreated and their travel documents were hidden thus rendering them as slaves.

In addition, Lebanon has been reported to be one of the global leaders in encouraging child labor. In reference to Saidi (2004), there has been a poor follow-up of corporate leadership as well as business ethics in Lebanon for the past few years and thus, around 1.9 percent of children between the ages of 9 and 14 were working and more than 92 percent of these children were not covered by any health insurance. During the year 2013, it was reported that many children in Lebanon engaged in child labor working in agricultural firms and in most deplorable labor conditions and commercial sex, drug trafficking, forced begging and some of these actions were successful because the country gave room for the human trafficking. Finally, according to Ammar, Wakim and Hajj (2007), there are numerous cases involving discrimination of more than 400,000 Palestinian who are denied by the government to own property and they are restricted from accessing the Lebanese healthcare. All these restriction and actions that are being undertaken by the government of Lebanon are considered a violation of human rights and failure to uphold the requirements stipulated in the ISO 26000 standards. The other subjects of the requirement by the ISO 26000 standards are the environment and fair operating practices. Lebanon is one of the countries across the globe that has failed terribly in ensuring proper conservation of the environment. For instance, the country encounters massive marine pollution that has been ranked among the top 20 in the world. The contributing factor to this issue is the failure to incorporate fully the ISO 26000 requirements to salvage the ecosystem of the country. Since the team of Lebanese navy that has been mandated the right to take care of the marine environment does not recruit specialized officers, the navy has limited skills due to limited human resources as well as equipment (Saidi, 2004) this has resulted in poor environmental conservation measures. To point out some of the long-term environment effects that Lebanon has undergone is the Jiyeh power station spill that took place in the year 2006 during Lebanon war. This disaster increased the risks of cancer as well as other diseases, besides it claimed the aquatic lives that ultimately resulted to no compensation and the scars of that disaster on the environment are still visible in Lebanon. Another environmental impact that Lebanese industries are withholding is the noxious liquid substances spills that include sulphuric acid and phosphoric acids that deliberately spills during the loading and offloading operations at Sellata Chemical Terminal to the environment at Chekka by industries that have failed to there to the international requirements standards. The release of these acidic contents to the environment has resulted in the death of animal, plants and pollution of soil and air. Such deliberate pollution of the environment is a clear indication that most of the industries in Lebanon have not adhered to the environmental safety standards and this applies not to the environment but also the health of the worker in these companies that is at high risk.

The other threat caused by the Lebanese industries to the environment is the release of ballast water and sewage to the environment. It has been established that the ballast water being discharged by those ships calling the port of Lebanon contain plants, viruses, bacteria and animals that posses a great danger to the ecosystem. According to Blowfield and Frynas (2005), this has not only been an issue to Lebanon but across the globe where many countries have failed in setting new agendas in relation to national social responsibility mostly in developing countries. For instance, the industries operating in Lebanon, most of them do not treat their wastes and raw sewage that is discharged from the residential homes in Lebanon is directed to water bodies that lead to the death of aquatic lives and both pollution of land and air. Despite such challenges that the country undergoes, the leadership has remained adamant in enacting laws that would enforce social responsibility through the adoption of the ISO 26000 Standards that could see the improvement of industrial operation and the general livelihood on the Lebanese.

Furthermore, another subject of ISO 26000 in relation to social responsibility and Lebanese industries is the consumer's issues. In Lebanon, the consumer protection law was passed in 2005 to ensure that the consumers are protected from misleading advertisements labeling and substandard products. However, this fight has not yielded much since the main production sources give birth to products used by the Lebanese have failed to effectively adopt the international safety requirements that would ensure production of quality products (Saidi, 2004).In this regard, even if the Lebanese government attempt to implement laws that protect the consumers, already the products themselves do not certify the international standards and, therefore, it could be advisable if the lawmakers in Lebanon would work towards ensuring that each and every company operating in the land adheres to the ISO 26000 standards. These standards will not only focus on the provision of quality 
products but also the general social responsibility that entails the good fare of the employees working in such companies, the impact of the companies to both the environment and the community. Putting such measures in place would see the country enact laws that would not only ensure the quality of the product but also the effectiveness of the entire production channel.

Furthermore, according to Pratima 2002, the corporate challenges of sustainable development have been attributed to delay in adoption of the standards due to fear of price and perception that they would counter the industrial production and growth. However, prior implementation of the ISO 26000 standards would ensure that the consumer needs are met before the products reach the market since it would counter the operation of greedy companies whose intention is to produce counterfeit products that do not meet international standards.

The final subject of consideration when implementing the ISO 26000 certification is the community involvement and development. Unlike in Lebanon whereby the elite manage all the industrial operation, it is a requirement that the community gets a chance to participate in the enforcement of social responsibility since it is the main stakeholder of any project in the country. Again, reports have confirmed that the majority of the Lebanese people live under absolute poverty that compelled them to engage in illegal businesses such as commercial sex and child labor. This is a clear indication that the social responsibility of both the government and the rest of the organizations in the country is compromised hence leading to deterioration of life. Additionally, since the government has failed to focus on enhancing the social responsibility of its citizens, then it would be cumbersome to implement any form of community development since the top leadership personnel in the land has corrupted the society all of its rights and privileges that are stipulated in the ISO 26000 report (Saidi, 2004).

ISO 26000 was intended to cover all types of organizations regardless the size, meaning both small, medium size and large have the right to acquire the certification. However, many countries have disagreed on how it is perceived to meet the needs of a small organization with perceptions that it was structured to for only renowned firms. However, it is because of its applicability to both the public and the private that give it the credibility of covering a diverse sector of industries.Human rights, the essential consequence is that the standard is organized to improve human rights where it can be smeared into the notion of practices. For instance, it has been proved that the standards contain powerful statements that instill moral and practical issues being encountered by companies since its introduction in the year 2010. The ISO 26000 is available by the national standard institutions across the globe for sale. The cost is determined by country's national standard institutions and it varies according to the economic state of the country, the level of the company which can either small medium or large. Besides, the standards are also available in various international languages such English, Arabic, French, Spain, and Dutch-Swedish among others.

Lebanon is perceived to be one of the countries with great potential but due to failures on the side of the government and pressure from her neighbors, the country has remained stagnant in its growth. Numerous factors have been obstructing the adoption of the ISO 26000 standards and the implementation of credible corporate social responsibility. Some of these factors include; corruption, Lebanon faces the problem of bureaucratic corruption that has been perceived to be supporting the current system of politics and the elite who benefit from it. Recently there has been credible evidence of the abuse of power and position in the system of bureaucracy besides other sectors of the economy. Research has established that Clientelism is mostly common amongst the Lebanese in particular concerning the role of religious elites who are connected to corruption scandals that make it very difficult to reform. Within the state, it has been established that every religious community always demands the containment of corruption as well as political transparency but achieving it is difficult because the people in power influence the pursuit of integrity. It has been difficult for the Lebanese to enforce integrity since all efforts towards forcing the government to act have been rendered futile. A lot of government resources are wasted on personal interested while the capital set for the public project are siphoned with, people who have been bestowed the mandate of implementing them. Failure to enforce social responsibility has cost Lebanon many resources that have become hard to account for, hence leaving blame to the top leadership of the country.

Another factor that needs to be addressed with urgency through the adoption of the ISO 26000 in Lebanon is the environmental pollution. This country has been rated among the top disastrous countries within Asia and such extreme environmental pollution has been propagated through ignorance and greed that has created a serious imbalance between the demographic tendencies, environmental protection and economic development. Statistics depict that in Lebanon, woods cover about 6 percents of the land while the fertile land amount to about 12 percent of the entire Lebanon's surface and researchers still confirm that they are quickly disappearing due to the growth of towns. However, unfortunately, the environmental policy that is followed by the Lebanese government since the early 1950s has been directed on the extension of the industrial field and the encouragement of exportation with few or no concern for environmental conservation. The Lebanese country mostly considers the condition of the good and products that come from the international market. According to Fulop, Hisrich and Szegedi (2000), much is expected but there is less concern by the key economic players to 
ensure that the local products that are produced by the local companies meet the international standards. For instance, the Lebanese market is based on supply and demand and mostly from the international market. The industries within the country have been granted free will of operation with the stipulation of environmental measures. According to Fulop, Hisrich and Szegedi, (2000), many companies deliberately fail to establish international standard marks of production and they ultimately end up producing low-quality products that do not meet international standards due to the free will of operation. In connection to that, since most of them do not put into consideration the required international standards, they fail to ensure proper employee social responsibility whereby the employees are forced to work under conditions that are hazardous to their health. Above all, they are not well compensated which leaves a question of what role should the government play to ensure that as much as the companies have not adopted the ISO 26000 standards, does they take care of their employees welfare? Within the Lebanese's economy, it has been established that the leaders do not care about the impact the free operating industries have to the environment. The main reason for this negligence is that most of the industries are state owned and these people affiliated with the government run them.

\section{Research Methodology}

The main research method employed in accessing information about the impact and limitation of ISO 26000 and the social responsibility of Lebanese industries include surveys carried out both online and one on one interviews with the Lebanese. These surveys were structured in always that they contained several questions about the subject of the research and posted online where the citizens of Lebanon were given a chance to participate by answering the questions. Besides, there were other surveys that were carried one on one in Lebanon where the citizens were specifically the those employed in industries were interrogated and gave their opinions concerning the subject of the research and this was perceived to be the effective methodology in getting credible information about social responsibility in Lebanese industries. The other method that was used is the administering of questionnaires that also worked hand in hand with the one on one surveys. Study of the historical data was also another method that was used to study the trend of social responsibility in Lebanese industries. This was done by looking at the history of industrial performance and how the welfare of the employees was taken into consideration and also how the community benefited from the industrial operations as well as the impact on the environment overtime. The three methods were used to access data and an analysis was done to find out whether Lebanon has had any change for last three decades in terms of improvement of social responsibility. Furthermore, the analyzed data would provide a way forward to on whether it would be helpful to have the adoption of the ISO 26000 standards or not. The analysis of this data is depicted in the tables and graphs section.

\section{Sampling Design}

This was another independent method that was mainly focused on determining the impact of Lebanese industries to the environment. For instance, samples of soil, water as well as air would be collected from various regions within the country and be analyzed and compared with the ones in areas dominated by the industries or in areas where the industries channel their waste products. This sampling of soil water and air would determine the ultimate impact of the industries to the environment and would provide an analysis of companies that have acquired the ISO 26000 Standards and those that have not and provide decisive recommendations on what should be done to ensure that the Lebanese industries do not directly affect the environment. The soils found in areas where the industries discard their waste products contain poisonous chemicals that cannot allow practices of agriculture on such soils. But for those soil collected in rural areas where there are no industries, the soil is fertile, well-aerated and supports agriculture and the same applies to water and air where the rivers that act as waste disposal terminals are polluted to an extent that they cannot support aquatic life. The recommendation for this sampling would be provided below at the recommendation stage.

\section{Research Design}

This research is designed to find out information about the impact and implication of ISO 26000 standards in the social responsibility of Lebanese industries so that credible conclusions can be obtained so that decisions can be made whether the standards are of great significance to the Lebanese industries or not. This research is also designed to present facts concerning the negative impacts that emerge because of failing to acquire the international standards, and these facts can be presented to the Lebanese government for evaluation and decision-making.

\section{Limitations}

The main limitations in relation to this research include

1. Denial for accessing sensitive information about social responsibility from the Lebanese ministry of labor.

2. Assessing the impact of corruption on people, community and the environment. 
3. Enforcing the adoption of the ISO 26000 standards to the Lebanese industries that might oppose since many of them would fear spending capital to acquire them

4. Reforming the labor sector which has been dominated by people who does not care about the welfare of others especially the welfare of the domestic workers and children

\section{Charts and Graphs}

The tables below represent the analysis of possible research and manipulation of data collected from various institutions and sectors of Lebanese economy to establish the impact, implication of failures to adopt the ISO 26000 standards and the current social responsibility state of the Lebanese industries and workforce.

\begin{tabular}{|l|l|l|}
\hline TYPES OF WORK & SALARY RANGE & ORIGIN \\
\hline Domestic workers & $\$ 100-200$ & Africa-Sri-lanka and Philippines \\
\hline Industrial casual laborers & $\$ 150-250$ & Africans, Philippines Sri-lanka and Palestine \\
\hline Secretaries, drivers etc & $\$ 200-350$ & Lebanese and Philippines \\
\hline Assistant supervisors/ supervisors & $\$ 360-1000$ & Lebanese \\
\hline Directors/ managers & $\$ 1001-1900$ & Lebanese \\
\hline Board of directors/ CEOs, politicians & Above $\$ 2000$ & Lebanese \\
\hline
\end{tabular}

The rate of unemployment in Lebanon as per the social responsibility situation

\begin{tabular}{|l|l|}
\hline Year & Unemployment Rate in \% \\
\hline 2008 & 7.2 \\
\hline 2009 & 6.2 \\
\hline 2010 & 6.2 \\
\hline 2011 & 6.2 \\
\hline 2012 & 10 \\
\hline 2013 & 6.2 \\
\hline 2014 & 6.4 \\
\hline
\end{tabular}

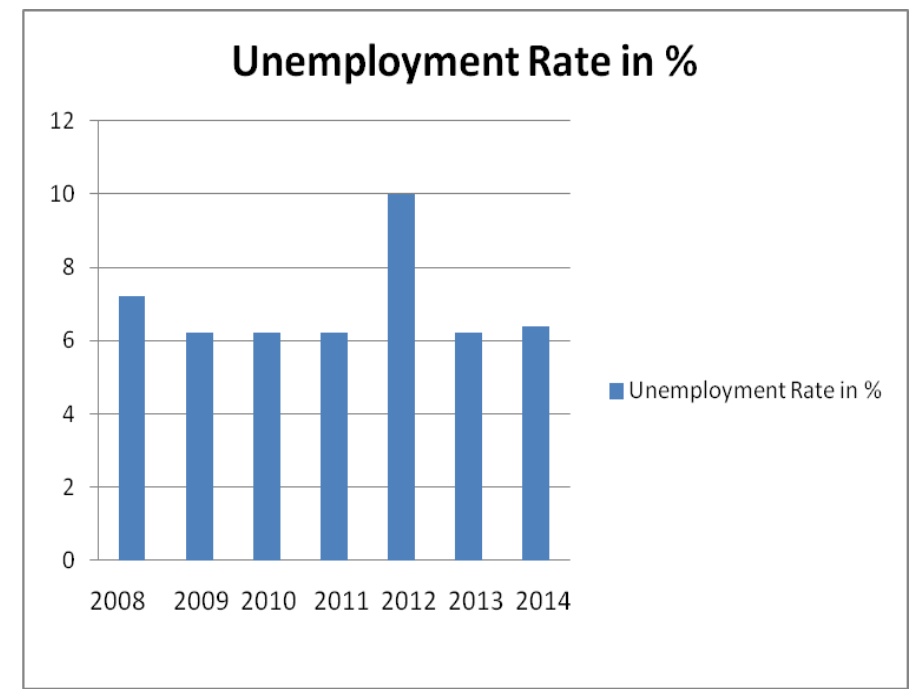

Findings

The majority of Lebanese are unemployed and they live under \$ 6 per day, and this is due to poor social responsibility. Most of the jobs are dominated by the elite first class group that controls the Lebanese industrial operations. The fact that the country harbors many refugees from Palestine, most of them serve as casual laborers in the industries and in the domestic sector, together with the immigrants from Africa, Philippines and Sri Lanka. The top executive jobs are held by people with great political influence and they control the Lebanese industrial operations. The unemployment rate was constantly decreasing from 2008 to 2011 then it drastically rose to $10 \%$ in 2012. A number of factors attributed to this increase in unemployment and these include; increase in the number of refugees, poor living conditions among the low-class group, and rise in cases of corruption in both the public sector and private sector that deterred economic growth hence the rise in unemployment. All these factors are directly related to failures on the side of the government to implement the International standards that would give guidelines on how to counter unemployment. Furthermore, another evident finding is the environmental pollution that has been on rise in Lebanon whereby it has been confirmed that currently, most of the garbage dumping sites have been closed due to poor managing and embezzlement of fund to manage the sites and as a result, garbage is carelessly dumped along the streets of towns in Lebanon. 


\section{Recommendations}

There is urgency in Lebanese industrial sector to formulate strategies that would enhance the workers conditions and the impact of the industries to the environment and community. The government should enforce laws that require all the companies to adopt the ISO 26000 Standards, in an effort to enhance social responsibility. The country should take the advantage of cheap labor provide by the refugees so that as to increase production level in the existing industries instead of restricting them from working in the country. The country should focus on empowering the local companies to evade reliance on the imports. This will also ensure that the local companies are given consideration and priority besides, enhancing their standards of operation hence effective corporate social responsibility. The country is affected by corrupt leaders and therefore, the Lebanese themselves should make a wise decision when it comes to the election so that the people who would be elected may be of integrity and ensure that all the resources are utilized effectively for the benefit of the workers, community and the environment.

\section{Conclusion}

Lebanon has great potential that can help the country grow economically in all sectors and this is due to available labor, resources and due to its strategic location. This means that there is a need to have visionary leaders that would have strategic plans focused on enhancing social responsibility. The ultimate solution to Lebanese industrial problems is the adoption of ISO 26000 standards and the election of new corruption-free leaders that would ensure full implementation of the country's laws and adoption of the prerequisite international standards. Taking such steps would ensure that the general welfare of the citizens together with the refugees and immigrants is enhanced and the environmental challenges are dealt with immediately when they arise.

\section{References}

[1]. Ammar, W., Wakim, R. and Hajj, I. (2007), “Accreditation of hospitals in Lebanon: a challenging experience”Vol. 13 No. 1, pp. $138-49$.

[2]. Azer, A. (2002), "The ethics of corporate responsibility: management trend of the new millennium?, Sheldon M. Chumir Foudation for Ethics in Leadership Report",

[3]. Belal, A. R. 2001. "A study of corporate social disclosures in Bangladesh.” Managerial Auditing Journal 16(5): 274-289

[4]. Blowfield, M. and Frynas, J. (2005), "Setting new agendas: critical perspectives on corporate social responsibility in the developing world", International Affairs, Vol. 81 No. 3, p. 501.

[5]. Fulop, G., Hisrich, R., and Szegedi, K. 2000. "Business ethics and social responsibility in transition economies." Journal of Management Development 19(1): 5-31

[6]. Fulop, G., Hisrich, R., and Szegedi, K. 2000. "Business ethics and social responsibility in transition economies." Journal of Management Development 19(1): 5-31

[7]. Hahn, R. (2012): "Standardizing Social Responsibility? New Perspectives on Guidance Documents and Management System Standards for Sustainable Development

[8]. Hahn, R. (2012): "Transnational Governance, Deliberative Democracy, and the Legitimacy of ISO 26000"

[9]. Lantos, G. P. 2002. "The ethicality of altruistic corporate social responsibility.” Journal of Consumer Marketing 19(3): 205-230

[10]. Luetkenhorst, W. (2004), "Corporate social responsibility and the development agenda",Intereconomics, Vol. 39 No. 3, pp. 15768.

[11]. Page, J. (2005), “Corporate governance and value creation”, Research Foundation of CFA Institute, University of Sherbrooke, Que bec.

[12]. Pratima, B. 2002. "The corporate challenges of sustainable development." Academy of Management Executive 16(2): 122-132.

[13]. Saidi, N. (2004), "Corporate governance \& business ethics in Lebanon", April 28, available at: www.rdcl. org.lb/nassersaidi.pdf

[14]. Schwarz, B. \& Tilling, K. (2009): "ISO-lating Corporate Social Responsibility in the Organizational Context: A Dissenting Interpretation of ISO 26000". In: Corporate Social Responsibility and Environmental Man

[15]. Snider, J., Ronald, P., and Martin, D. 2003. "Corporate social responsibility in the 21st century: A view from the world's most successful firms.” Journal of Business Ethics 48(2): 175-187.

\section{Appendices \\ Appendix I: Lebanese industrial distribution and population}

Lebanon population amounts to approximately 5.9 million.

Total fertility rate is 1.74 children while life expectancy is 77.22 years for male and 76.03 for women

The total age dependency ratio is $47.1 \%$, which is relative below average, and this indicates that this type of population is less than $50 \%$ of the total working population. While the rate of male literacy is, $95.97 \%$ and 91.85 for female while the overall literacy for the youth is $99.09 \%$

Women representation in parliament amounts to $3.1 \%$ and female over 25 years of secondary education represents $53 \%$. While women in labor force represent $22.6 \%$

Lebanese female global gender gap index is 0.6028 in the year 2011 and the country is ranked 123 out of 136 globally.

\section{Appendix II: Lebanese Economic Status}

Lebanon annual government budget amounts to approximately, -749781 LBP Million. The annual export amounts to\$228 million and the imports \$1377 million. 
The rate of inflation is at $-2.94 \%$ and the rate of food inflation is at $-2.05 \%$ while the consumer price index is approximately 94.35 points. The Lebanon government revenue ranges from 961596 LBP Million while the government budget ranges from $5.4 \%$ of its GDP. The unemployment rate is at an average of $6.4 \%$. Poor strategic planning and failure of the government to enforce international standards in its key economic players besides rampant cases of corruption contribute all these factors.

\section{Appendix III: community and environmental implication of ISO 26000}

The majority of the population comprises of the lower class people. Though the rate of literacy is high, most of the people work in private sector hence less is given back to the community. Community projects are hampered by rampant cases of corruption due to lack of integrity amongst the elective leaders. Poor safety standards for the community have resulted in cases of communicable diseases, which are dominant in most developing countries. Poor corporate social responsibilities due to poor compensation for the majority of workers and risky working conditions are practiced in Lebanese industries. As a result, the impact of all failures to enforce punitive measures to curb environmental pollution leads to the deplorable living environments and conditions such as reckless disposal of garbage and poisonous chemical to water, air and soil. 